\section{Poesía ambioua: género, deseo y lenguaje}

\section{Daphne Colette Díaz-Gutiérrez}

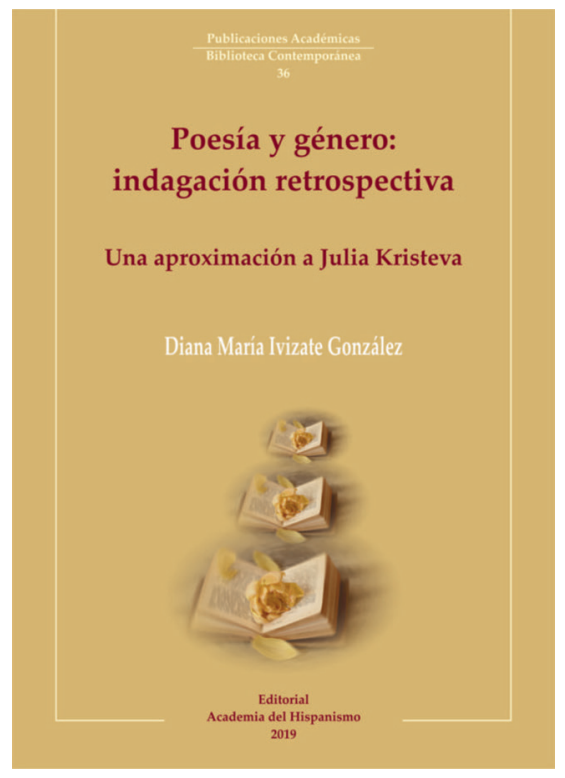

Diana María Ivizate González, Poesía y género: indagación retrospectiva. Una aproximación a Julia Kristeva, ISBN: 978-84-17696-19-1, Vigo, Editorial Academia del Hispanismo, 2019, $88 \mathrm{pp}$.

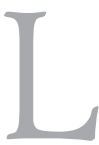

a poesía, más que un arte, es un ejercicio de autoconocimiento; por medio de ella, el individuo puede acceder a los rincones más profundos de su pensamiento al liberarse de estereotipos y cargas que le han sido impuestas por la sociedad, pero de las cuales se ha apropiado íntimamente en su desarrollo, por ejemplo, el género, tema central de este libro. ¿Cómo siente una mujer? ¿Cómo desea? ¿Existe un pensamiento propiamente femenino o uno masculino? ¿Acaso el género de la persona determina su relación con el mundo y consigo misma?

Ivizate se cuestiona "¿Puede la poesía metafísica suprimir el género?" (37); ${ }^{1}$ su libro constituye una amplia respuesta afirmativa a esa pregunta central. En estas páginas se abordan temas como el psicoanálisis, los estereotipos de género, tanto masculinos como femeninos, y la poesía feminista contemporánea. La investigación demuestra que el lenguaje, mecanismo por el cual se construye la identidad de género, puede también ser una herramienta para desdibujarlo o tornarlo ambiguo en la poesía (11), en especial desde lo femenino. La autora afirma que "existe en nosotras mismas la capacidad de crear una identidad fuera de las categorías discursivas impuestas o de disolver esa identidad", y se remite a su propia experiencia poética para ilustrar "lo que puede hacer por nosotras la poesía como diálogo intra-personal, es decir, revuelta íntima" (17-20).

Para demostrar su tesis, la investigadora la ejemplifica con poemas propios, menciona su proceso creativo personal, el manejo que su inconsciente hizo de las palabras al momento de crear sus textos y cómo, tiempo después, descubrió lo que su obra decía sobre ella como individuo, sus procesos de duelo y la manera en que el género podía estar (o no) determinando su manera de relacionarse con el mundo. De esta manera, Ivizate reflexiona sobre el sujeto lírico en su producción, tomando en consideración que la psique individual está permeada por el género normalizado en la cultura de quien escribe. Plenamente consciente de que ella, como persona y como poeta, no es capaz de desprenderse del todo de los roles que se le han adjudicado en lo social, explica: "la escritura me ha proporcionado un relato de lo que he sido, como sujeto histórico, y a la vez, como individuo" (26).

1 Todas las citas pertenecientes a Poesía y género: indagación retrospectiva. Una aproximación a Julia Kristeva corresponden a Ivizate González (2019), por lo cual sólo se anota el número de página. 
Para demostrar que el género y sus atributos no son sino una imposición, la autora cita a estudiosas como Judith Butler, Simone de Beauvoir y Julia Kristeva, y aborda conceptos como la 're-vuelta' íntima y la 'heterosexualidad obligatoria', términos distantes entre sí pero que, al relacionarse, dan paso a la introspección y al cuestionamiento de los propios deseos —ison realmente nuestros o nos han sido, quizá, sutilmente implantados?-. De esto último se desprende el tema lésbico en la poesía, con ejemplos de textos elaborados por la misma autora, así como por otras escritoras contemporáneas. La poesía lésbica proporciona una alternativa a la imposición social de la heterosexualidad, pues carece del sentido de dominación y de la relación de poder típica de un vínculo de este último tipo. Así, expone que se puede "establecer una fuerte relación del deseo con el lenguaje sin que ese deseo pertenezca a un género determinado, sin que el varón subordine a la hembra, sin que el éxtasis se alcance sólo mediante la subordinación del sexo femenino" (38).

Cada parte del libro - un texto breve y rotundo- es sustancial para comprender la propuesta de Ivizate acerca del género y su ambigüedad en la poesía, en especial, tres capítulos. "¿Qué es lo femenino en el mundo masculino?" presenta de manera concisa la problemática de la división de los géneros en una jerarquía en la cual la mujer funge como servidora y subordinada de los deseos del varón y es incapaz de tener los propios. Por su parte, los capítulos "Estereotipos femeninos" y "Estereotipos masculinos" tienen como objetivo evidenciar los roles que se han adjudicado a ambos géneros, su implicación negativa para los individuos y la desigualdad que propician.

Las mujeres son estereotipadas como 'la heroína romántica', que necesita ser salvada y no puede actuar por sí misma; 'la puta', sexualmente disponible para la satisfacción de los deseos carnales del hombre; y 'la virgen', que es 'pura' por no haber tenido contacto sexual, por ser ignorante tanto en esta cuestión como en cualquier otra de un mundo en el cual no tienen cabida, pues su lugar está en lo privado (66-69). Identificar estos estigmas con los que las mujeres hemos cargado durante mucho tiempo nos permite evidenciar el papel de sumisión que una sociedad patriarcal ha designado para el sexo femenino en Occidente. Claramente, en otras culturas también existe la distinción entre géneros; pero Ivizate aclara que en su investigación sólo habla del caso occidental al tratarse de situaciones distintas.

Los estereotipos masculinos (71) no podían ser dejados a un lado. La autora reconoce que la sociedad beneficia al varón al darle 
más poder, esto también implica, al igual que para las mujeres, una presión con la que no todos están dispuestos a cargar. Los roles del hombre giran en torno al 'dominio', concepto central de la masculinidad occidental. El ejemplo que la investigadora proporciona es el de Franz Kafka y su Carta al padre. La epístola alude reiteradamente a las características a las que el joven escritor aspiraba, todas personificadas en su progenitor: la fortaleza física, el carácter vigoroso, la afición al alcohol y a la comida, incluso los posibles oficios que eran dignos para un varón. Al igual que las mujeres, asegura la autora del libro, los hombres en la actualidad reflexionan sobre las implicaciones negativas que los estereotipos de género tienen para todos los individuos, y los estudios de las nuevas masculinidades constituyen un avance en la deconstrucción de estas normas tan arraigadas en la cultura.

"La narración como supervivencia" (78) es el penúltimo capítulo del libro. Considerando su brevedad, bien podría tomarse como la primera parte de la conclusión, pues los apartados previos de cierta manera guían al lector hasta la reflexión que se hace aquí sobre lo importante que es —en especial para las mujeres - la escritura creativa. Desde Virginia Woolf hasta Ana Frank, existen numerosos ejemplos - anónimos, en muchos casos- de cómo las artes han permitido a las mujeres desprenderse de los roles de sumisión que la sociedad patriarcal les ha impuesto, así como descubrir que tienen deseos, pensamientos y sentimientos propios que no están subordinados a la aprobación o a la necesidad masculina. Aunque la pintura, la música, la danza y otras artes permiten a las mujeres acercarse al placer de la creación y al descubrimiento de sí mismas, la escritura implica poner en palabras lo emocional.

Aquello que en la cotidianidad es difícil de nombrar y todavía más complicado ejercer — la libertad, el poder-, ha sido alcanzado por muchas mujeres en la íntima relación con las palabras. Y si bien la narración permite racionalizar la inconsciente (78), por ejemplo, mediante los diarios, las cartas o el desarrollo de ficciones, la poesía nos libera mayormente de la estructura lógica, nos deja más con las palabras desnudas y solas que con las frases coherentes de la prosa.

Tal como menciona Ivizate, usando como ejemplo sus propios poemas, la poesía no es, a diferencia de la narrativa, la racionalización de las emociones inconscientes, sino su verbalización. La práctica poética permite desapegarse de lo que sabemos para aventurarnos a lo que desconocemos de nosotras mismas, lo que nos ha sido arrebatado y, aún en la actualidad, sigue velado por la carga de género impuesta desde hace siglos. 
Escribir poesía nos da la oportunidad de liberarnos de lo racional para comprender lo irracional: lo abstracto, lo emotivo y lo inconsciente, por lo cual podría decirse que escribir -insisto, sobre todo, poesía - es tender un puente de palabras entre la razón y el íntimo deseo.

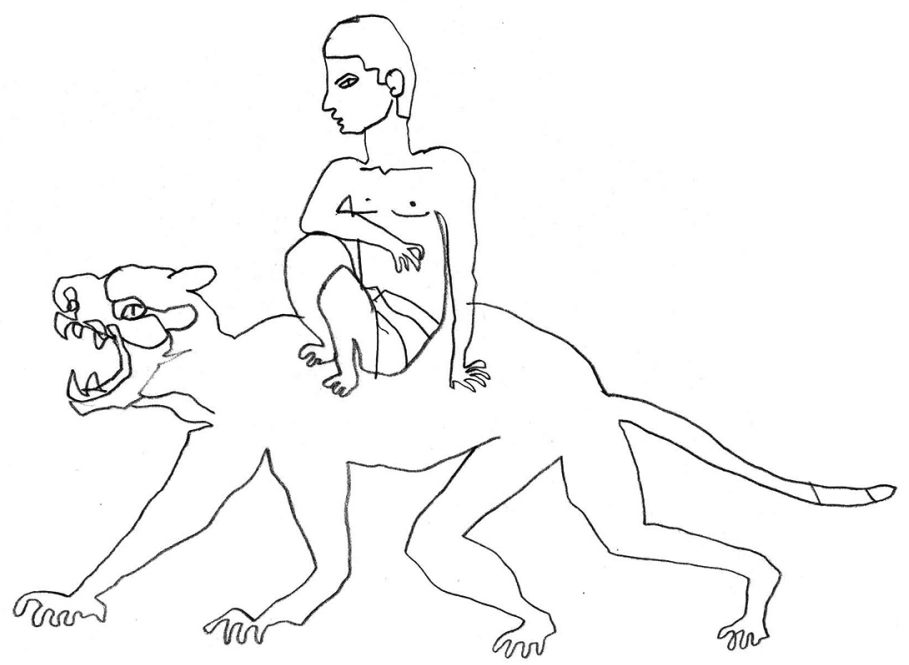

Niño y jaguar, de la serie Dibujo simple (2018). Lápiz: Carlos Alberto Badillo-Cruz Prohibida su reproducción en obras derivadas.

Daphne Colette Díaz GutiérRez. Estudiante del último semestre de la Licenciatura en Comunicación por la Universidad Autónoma del Estado de México (UAEM), México. Correctora de estilo y asistente editorial especialista en publicaciones periódicas. Ha incursionado también en la escritura creativa. 